\title{
Application of Analytical Hierarchy Process in Teaching Quality Analysis of English Writing
}

\author{
https://doi.org/10.3991/ijet.v15i14.15359 \\ Xiaoqin Zhang \\ Yuncheng Advanced Normal College, Yuncheng, China \\ Shengxin Wang \\ Southwest University, Chongqing, China \\ Yanling Cao $(\bowtie)$ \\ South China University of Technology, Guangzhou, China \\ sdylcaodscut.edu.cn \\ Guangqi Chen \\ Kangjie Middle School, Yuncheng, China
}

\begin{abstract}
There are two major problems in the evaluation of the teaching quality of English writing: the weak logic of the evaluation system and the low reliability of the evaluation model. To solve the problems, this paper put forward an evaluation method for the teaching quality of English writing based on the analytical hierarchy process (AHP). Firstly, the authors reviewed the current evaluation methods for the teaching quality of English writing. Next, hierarchical evaluation systems were established for the teaching quality of English writing from the perspectives of teachers and students, respectively. After that, the AHP method and the grey theory were introduced to set up an evaluation model for the teaching quality of English writing. Finally, several strategies were presented to improve the teaching quality of English writing. The proposed evaluation systems and model enriched the theories on teaching quality evaluation of English writing, and promoted the teaching quality of English writing.
\end{abstract}

Keywords-English writing, teaching quality, analytical hierarchy process (AHP), grey theory, strategies

\section{Introduction}

As an international language, English plays a very important role in people's international cooperation and exchanges. We all know that higher education is a talent education mode aiming to cultivating talents with advanced skills and high qualities, it emphasizes the cultivation of comprehensive qualities of the students [1,2], which makes English teaching occupy a very important position in higher education, and more and more higher education schools and educators are beginning to attach great 
importance to the quality of English teaching [3-5]. As a key part of English teaching, the teaching of English writing is one of the main links in English teaching and it interacts with other links such as English listening, speaking, reading and translating, etc.; when applying English for written expression, the teaching of English writing plays a decisive role in the quality and effect of English expression. Therefore, the research on English teaching, including English writing teaching, has gradually become a hot topic in linguistic research [6,7].

Currently published English teaching research results include main teaching links such as listening, writing, speaking, reading and translating, they have good reference significance for instructing the teaching of English writing from the perspective of the integration and integrity of English teaching, and they have a positive and promotive role in improving the teaching quality of English writing, for instance, Kim-Daniel Vattøy and others discussed students' feedback in English teaching [8]. Xuan Nhat Chi Mai Nguyen and others discussed the autonomy of English teachers in teaching practice [9]. Derek Irwin et al. proposed the concept of transforming general knowledge into the teaching of English academic writing [10]. CAO and others studied the innovation of the reform modes of college English writing teaching [11]. YANG analyzed the positive role of multimedia-assisted teaching in the basic writing of college English courses [12]. CAO comparatively analyzed the influence of peer feedback and teacher feedback on college students' English writing teaching [13].

However, it can be seen that the current evaluation dimensions and perspectives for the teaching quality analysis of English writing are diverse and not uniform, which poses certain limitations on the application of teaching quality analysis methods of English writing. At the same time, because different evaluation dimensions and perspectives tend to focus on partial links of English writing, this often leads to a lack of integrity in the teaching quality analysis of English writing. Therefore, there're still rooms for further research on the teaching quality analysis of English writing. To this end, based on existing research results, this paper combined AHP method [14, 15] with grey theory $[16,17]$ to study methods for the teaching quality analysis of English writing. The content of this paper includes 6 parts. The first part summarizes current researches on the competitiveness of higher education. The second part analyzes the methods of teaching quality analysis of English writing involved in the construction process of the proposed method in this paper. The third part establishes hierarchicalstructured evaluation systems for the teaching quality of English writing. The fourth part constructs an evaluation model for the teaching quality of English writing based on AHP. The fifth part discusses the related strategies and measures to improve the teaching quality of English writing. The sixth part gives the conclusions. 


\section{Application Methods for Teaching Quality Analysis of English Writing}

\subsection{Literature review}

The teaching quality analysis of English writing is a systematic research project. In this process, solid accumulation and practical verification of the teaching theories of English writing are required; to fully master the development status and application level of current research content, it's necessary to collect, summarize and organize a large number of related studies, and form a theoretical system and application framework for the teaching quality analysis of English writing through literature review.

\subsection{Expert consultation}

English teachers and teaching experts, especially first-line English teachers with special achievements in English writing, their experience and suggestions could provide useful guidance for the planning and implementation of English writing teaching. With their knowledge, experience, and analysis and judgement abilities in English writing, they could give instructions to the viewpoints, suggestions and schemes in the teaching quality analysis of English writing, which has very important significance for the smooth implementation of English writing teaching and teaching quality analysis, and it provides a direct path for the teaching quality analysis of English writing.

\subsection{Questionnaire survey}

The process of the teaching quality analysis of English writing includes two parts: the teacher group and the student group. The teaching quality of English writing is jointly determined by the two groups: one is the teacher group's knowledge transfer, namely the "teaching" factor, which could be collected through expert consultation; the other is the student group's knowledge absorption, namely the "learning" factor, to obtain effective analysis results of the student group, it is necessary to study a certain number of individual students under specific analysis objects or targets, and effectively analyze the characteristics of their demands. The questionnaire survey method has provided an effective solution for this. By designing a questionnaire for the teaching quality of English writing, surveys could be conducted among students, which has a very positive role in promoting the teaching quality of English writing, and providing a direct path for the teaching quality analysis of English writing.

\subsection{Statistical analysis}

The process of the teaching quality analysis of English writing involves many influencing factors, and some influencing factors cannot be obtained intuitively, but need to be processed by statistical analysis methods, that is, to collect, summarize and organize various materials, data and knowledge concerning the teaching quality anal- 
ysis of English writing, and use mathematical methods to calculate, analyze, understand, and discover the interactions, relationships, variation laws and development trend of the influencing factors of the teaching quality of English writing, and then on this basis, propose conclusions, strategies and countermeasures for the promotion of the teaching quality of English writing.

\section{Hierarchical Evaluation Systems for the Teaching Quality of English Writing}

\subsection{Principles for evaluation indicator selection}

The teaching quality analysis of English writing is a systematic project. As many influencing factors and constraints are involved in the analysis process, if the evaluation indicators are not properly selected, they would directly affect the accuracy and reliability of the analysis results, therefore, there are a few basic principles that should be followed concerning the selection of the evaluation indicators for the teaching quality analysis of English writing, as shown below:

1. Systematic principle. The teaching quality analysis of English writing is an organic whole. The evaluation indicators should not only reflect the main characteristics and status of the key influencing factors, but also reveal the internal logical relationship among these factors. The evaluation indicators should be independent of each other and correlated to each other, and there's a top-down hierarchical structure in these indicators, which could refine the analysis process of the teaching quality of English writing into smaller details, thereby forming a systematic evaluation system.

2. Scientific principle. The selection of evaluation indicators for the teaching quality analysis of English writing must be able to truly and objectively reflect the characteristics and status of the key factors in the teaching process, the evaluation indicators should have scientific and reasonable meanings, and can reflect the interactions and relationships among the indicators, thereby providing a scientific basis for the construction of the evaluation system of the teaching quality of English writing.

3. Typical principle. There are many influencing factors involved in the teaching quality analysis of English writing. Due to the complex interactions among these influencing factors, it's not that the more the indicators, the better; more indicators often mean that it's difficult to effectively separate the internal relationships and the process is very complicated; however, it's not that the less the indicators, the better either, less indicators would result in blur evaluation boundaries. As a result, the evaluation indicators must have certain representativeness and can accurately reflect the comprehensive characteristics of the teaching quality analysis of English writing, and a proper number of evaluation indicators should be selected to ensure the reliability and accuracy of the evaluation results. 
4. Objective principle. The objective principle means that the selection of the evaluation indicators for the teaching quality analysis of English writing should be based on the objective facts and actual conditions of the English writing teaching process; vague, general and inaccurate evaluation indicators should be avoided, especially subjective or impractical indicators should not be chosen, so as to ensure the objectivity, authenticity and reliability of the evaluation results.

5. Operable principle. There are many types of evaluation indicators in the teaching quality analysis of English writing, and different type indicators have different expression methods, which results in poor operability of the evaluation indicators, thereby affecting the reliability and accuracy of the evaluation results. To this end, when selecting the indicators, the operability of the indicators should be taken into consideration so that within the overall evaluation range, the indicators could have a unified measurement and calculation method, and it should be conductive to the conversion between qualitative evaluation indicators and quantitative evaluation indicators and the calculation analysis.

\subsection{A hierarchical evaluation system based on the perspective of teachers}

The hierarchical evaluation system based on the perspective of teachers was constructed for the teacher group, this system mainly focuses on how English writing teachers give English writing courses and the teaching effects of the lecturing process, it evaluates and analyzes the teaching quality of English writing from the perspective of the "teaching" of teachers. The hierarchical evaluation system was divided into three parts: teaching preparation A1, teaching implementation A2, and teaching effect A3. The teaching preparation link examines the teachers' ability in preparing the English writing courses, it includes the following aspects: teaching ability a11, teaching task formulation a12, teaching goal setting a13, teaching plan writing a14, teaching attitude a15, and teaching instruments a16. The teaching implementation link examines the teachers' ability in course lecturing, it includes the following aspects: teaching method a21, teaching concept a22, teaching content a23, teaching tools a24, and classroom atmosphere a25. The teaching effect examines the outcome of the English writing courses taught by the teachers, it includes the following aspects: task completion a31, textbook compilation for English writing courses a32, number of educational reform projects undertaken a33, the number of teaching awards received a34, the number of papers concerning teaching and teaching reform published a35, and the construction of English writing knowledge base/database a36.

\subsection{A hierarchical evaluation system based on the perspective of students}

The hierarchical evaluation system based on the perspective of students was constructed for the student group, this system mainly focuses on how students learn English writing in the class and the learning effect of the English writing, it evaluates and analyzes the teaching quality of English writing from the perspective of the "learning" of students. The hierarchical evaluation system was divided into three parts: learning preparation B1, learning implementation B2, and learning effect B3. The learning 
preparation link examines the students' ability in preparing the English writing courses, it includes learning attitude b11, learning task formulation b12, autonomous learning ability b13, and pre-class preparation b14. The learning implementation link examines the students' ability in course learning, it includes the following aspects: learning participation b21, learning concentration b22, learning methodology b23, learning enthusiasm b24, and learning satisfaction b25. The learning effect examines the outcome of the English writing courses, it includes the following aspects: English writing ability b31, innovation ability b32, listening-speaking-reading-writing integration ability b33, exam pass rate b34, exam excellent rate b35, and English writing competition awards b36.

\section{$4 \quad$ AHP-Based English Writing Teaching Quality Evaluation Model}

Based on the above discussion, the evaluation system of the teaching quality of English writing was taken as the target layer, the teachers' and students' perspectives were taken as the criterion layer, and the evaluation indicators under each criterion layer were taken as the indicator layer, and a hierarchical evaluation system of the teaching quality of English writing was constructed as shown in Fig. 1.

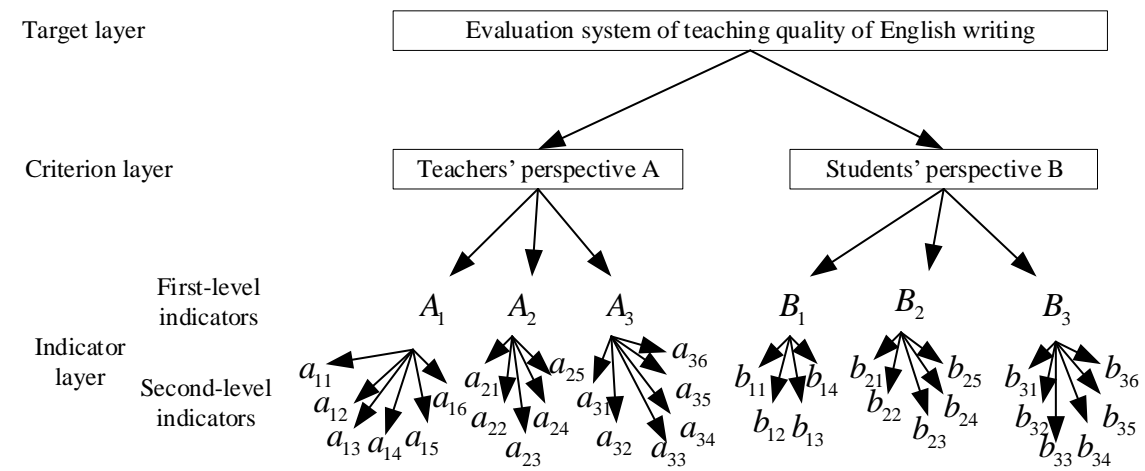

Fig. 1. Evaluation system of the teaching quality of English writing

\subsection{Weights of evaluation indicators}

From the evaluation system we can see that, the evaluation indicators under different criteria and layers had different degrees of importance, therefore, different weights should be assigned to these evaluation indicators. This paper adopted the AHP [1822] method to analyze the weights of the evaluation indicators.

By referring to expert opinions, the 9-point scale method was adopted to conduct pairwise comparisons on the evaluation indicators under the same level, and a judgment matrix of the teaching quality of English writing was constructed and marked as $\mathrm{R}$ : 


$$
\boldsymbol{R}=\left[\begin{array}{ccccc}
r_{11} & \cdots & r_{1 j} & \cdots & r_{1 n} \\
\vdots & \cdots & \vdots & \cdots & \vdots \\
r_{i 1} & \cdots & r_{i j} & \cdots & r_{i n} \\
\vdots & \cdots & \vdots & \cdots & \vdots \\
r_{n 1} & \cdots & r_{n j} & \cdots & r_{n n}
\end{array}\right]
$$

where, $n$ is the number of evaluation indicators in a same level, it satisfies $1 \leq i, j \leq n$; rij represents the judgement value of evaluation indicator i relative to evaluation indicator $\mathrm{j}$, and it satisfies rij*rji $=1, \frac{1}{9} \leq r_{i j}, r_{j i} \leq 9$, the specific values and the corresponding meanings of rij are shown in Table 1.

The maximum eigenvalue $\lambda_{\max }$ and the corresponding eigen vector $\mathrm{W}$ of the above judgment matrix were calculated, and the eigen vector was subject to normalization processing, the weights wi of the corresponding evaluation indicators were obtained.

$$
\begin{gathered}
w_{i}=\sqrt[n]{\prod_{j=1}^{n} r_{i j}} / \sum_{k}^{n} \sqrt[n]{\prod_{j=1}^{n} r_{k j}}, 1 \leq i, j, k \leq n \\
\lambda_{\max }=\sum_{i=1}^{n}(\boldsymbol{R} * W) /\left(n * w_{i}\right)
\end{gathered}
$$

To judge the rationality of the obtained weights wi of the evaluation indicators, consistency check was performed, that is:

$$
\left\{\begin{array}{l}
C I=\left(\lambda_{\max }-n\right) /(n-1) \\
C R=C I / R I
\end{array}\right.
$$

where, CI represents the consistency index, CR represents the consistency ratio, RI represents the random index, their values can be obtained by referring to Table 2 .

Table 1. Contents and meanings of the 9-point scale method

\begin{tabular}{|c|l|}
\hline Content & \multicolumn{1}{|c|}{ Meaning } \\
\hline 1 & Indicators $i$ and $j$ are equally important \\
\hline 3 & Indicator $i$ is slightly more important than indicator $j$ \\
\hline 5 & Indicator $i$ is more important than indicator $j$ \\
\hline 7 & Indicator $i$ is obviously more important than indicator $j$ \\
\hline 9 & Indicator $i$ is extremely more important than indicator $j$ \\
\hline $2,4,6,8$ & Intermediate states between the above states \\
\hline Reciprocal & Judgement value of indicator $j$ relatively to indicator $i$, it satisfies $r_{i j}{ }^{*} r_{j i}=1$ \\
\hline
\end{tabular}


Table 2. RI values

\begin{tabular}{|c|c|c|c|c|c|}
\hline $\mathbf{n}$ & $\mathbf{1}$ & $\mathbf{2}$ & $\mathbf{3}$ & $\mathbf{4}$ & $\mathbf{5}$ \\
\hline $\mathrm{RI}$ & 0 & 0 & 0.58 & 0.90 & 1.12 \\
\hline $\mathrm{n}$ & 6 & 7 & 8 & 9 & 10 \\
\hline $\mathrm{RI}$ & 1.24 & 1.32 & 1.41 & 1.45 & 1.49 \\
\hline
\end{tabular}

If $\mathrm{CR}<0.1$ is satisfied, it means that the judgment matrix meets the requirements of the consistency check, the obtained weights are reasonable; otherwise, the judgment matrix needs to be re-constructed so that it could satisfy the requirements of the consistency check.

\subsection{Processing of evaluation indicators}

Suppose there're $m$ evaluation objects in the teaching quality analysis of English writing, the value of the $\mathrm{i}$-th evaluation object relative to the $\mathrm{j}$-th evaluation indicator was vij. This paper considered that the evaluation indicators included two forms: positive indicators and negative indicators. If the $\mathrm{j}$-th evaluation indicator is a positive indicator, then the normalized value uij of the $\mathrm{i}$-th evaluation object relative to the $\mathrm{j}$-th evaluation indicator is:

$$
u_{i j}=\frac{v_{i j}-\min _{1 \leq i \leq m}\left(v_{i j}\right)}{\max _{1 \leq i \leq m}\left(v_{i j}\right)-\min _{1 \leq i \leq m}\left(v_{i j}\right)}
$$

If the $\mathrm{j}$-th evaluation indicator is a negative indicator, then the normalized value uij of the $\mathrm{i}$-th evaluation object relative to the $\mathrm{j}$-th evaluation indicator is:

$$
u_{i j}=\frac{\max _{1 \leq i \leq m}\left(v_{i j}\right)-v_{i j}}{\max _{1 \leq i \leq m}\left(v_{i j}\right)-\min _{1 \leq i \leq m}\left(v_{i j}\right)}
$$

After normalization, the evaluation indicators had a uniform measurement standard, the differences among indicators were eliminated, it satisfied $0 \leq u i j \leq 1$.

\subsection{Grey relational analysis model (GRA model)}

The grey relational analysis method can well solve problems such as small sample number, lack of information and ambiguity in complex system analysis by conducting grey relational ranking on the features or factors of system decision analysis, it has a good application prospect in the field of engineering [23-25]. To this end, by processing the normalized value uij of the evaluation indicators, a positive grey relational sequence $\mathrm{U}+$ was constructed, that is:

$$
U^{+}=\left\{u_{j}^{+}\right\}_{1 x n}=\left\{\max _{1 \leq i \leq n}\left(u_{i j}\right)\right\}_{1 x n}
$$


Similarly, the negative grey relational sequence U- was constructed as well, that is:

$$
U^{-}=\left\{u_{j}^{-}\right\}_{1 x n}=\left\{\min _{1 \leq i \leq n}\left(u_{i j}\right)\right\}_{1 x n}
$$

The grey relational coefficient $\rho_{i j}^{+}$of the i-th evaluation object relative to the $\mathrm{j}$-th evaluation indicator and the positive grey relational sequence $\mathrm{U}+$ was:

$$
\rho_{i j}^{+}=\frac{\min _{i} \min _{j}\left|u_{j}^{+}-u_{i j}\right|+\beta \max _{i} \max _{j}\left|u_{j}^{+}-u_{i j}\right|}{\left|u_{j}^{+}-u_{i j}\right|+\beta \max _{i} \max _{j}\left|u_{j}^{+}-u_{i j}\right|}
$$

where, $\beta$ is the identification coefficient, generally takes $\beta=0.5$.

The grey relational coefficient $\rho_{i j}^{-}$of the i-th evaluation object relative to the j-th evaluation indicator and the negative grey relational sequence U- was:

$$
\rho_{i j}^{-}=\frac{\min _{i} \min _{j}\left|u_{j}^{-}-u_{i j}\right|+\beta \max _{i} \max _{j}\left|u_{j}^{-}-u_{i j}\right|}{\left|u_{j}^{-}-u_{i j}\right|+\beta \max _{i} \max _{j}\left|u_{j}^{-}-u_{i j}\right|}
$$

The weighted grey relational degree $\eta_{i}^{+}$of the i-th evaluation object relative to the $j$-th evaluation indicator and the positive grey relational sequence U+ was:

$$
\eta_{i}^{+}=\sum_{j=1}^{n}\left(w_{i} * \rho_{i j}^{+}\right)
$$

The weighted grey relational degree $\eta_{i}^{-}$of the i-th evaluation object relative to the $\mathrm{j}$-th evaluation indicator and the negative grey relational sequence $\mathrm{U}$ - was:

$$
\eta_{i}^{-}=\sum_{j=1}^{n}\left(w_{i} * \rho_{i j}^{-}\right)
$$

Therefore, the comprehensive weighted grey relational degree $\eta_{i}$ of the i-th evaluation object relative to the $j$-th evaluation indicator and the grey relational sequences was:

$$
\eta_{i}=1 /\left(1+\left(\eta_{i}^{-} / \eta_{i}^{+}\right)^{2}\right)
$$

It can be seen that the greater the value of the comprehensive weighted grey relational degree $\eta_{i}$, the higher the teaching quality of the i-th evaluation object; conversely, the smaller the value of the comprehensive weighted grey relational degree $\eta_{i}$ 
, the lower the teaching quality of the i-th evaluation object. According to this, effective judgement of the teaching quality of English writing could be achieved.

\section{$5 \quad$ Strategies for Improving the Teaching Quality of English Writing}

\subsection{Improve the teaching mode}

It can be seen from the implementation process of English writing courses in colleges and universities that the current teaching mode of English writing courses focuses on the systemic teaching mode, that is, teachers give systematic lectures and students memorize and learn them systematically, this teaching mode has good logic and systematicity, which is conducive to the collective teaching of English writing knowledge within the range of the curriculum planning system; however, this teaching mode has certain limitations in the transmission of English writing knowledge points, the cultivation of autonomous learning ability in English writing, and students' self-cognition ability in English learning, it cannot effectively stimulate students' interests in learning English writing, resulting in that students lack of enthusiasm or initiative in English writing courses. To this end, based on the traditional systematic English writing teaching mode, we should integrate it with the procedural English writing teaching mode, the heuristic English writing teaching mode, and the nondirective English writing teaching mode, thereby making the teaching mode more procedural, the teaching content more systematic, the learning process more autonomous, and the learning cognition more methodical.

\subsection{Enrich the teaching content}

The teaching content of English writing refers to the dynamic and developable materials, knowledge and information used in the interaction among teacher and student groups for the purpose of serving the teaching of English writing during the implementation process of the English writing courses. It can be seen that the teaching content of English writing is not limited to textbooks only, and the teaching of English writing shouldn't be implemented only around a single English writing course standard. The traditional English writing courses simply equate the textbooks with the teaching content, it's generally believed that teachers should teach what is inside the textbooks according to the course standards. This viewpoint is narrow, and it cannot effectively teach English writing knowledge from multiple perspectives, fields, levels, and dimensions, and it has great deficiencies in improving students' English writing ability. To this end, we must realize that textbooks are only one carrier for the teaching content of English writing, if we want to effectively improve students' English writing ability, we must reform the teaching of English writing courses, keep pace with the development of times, and constantly enrich the teaching content. 


\subsection{Enhance teaching faculty}

The teaching faculty is the primary condition for improving the quality of English teaching. Only with a competent faculty can the teaching quality of English writing be improved effectively. The English teaching faculty can be enhanced through the following aspects: first, strengthen the professional ability and literacy of English teachers through various forms such as professional training, academic exchanges, and demonstration classes given by famous teachers; second, pay attention to the construction of English teaching talent teams with teachers of different ages and professional levels by introducing senior teaching talents at home and abroad or cultivating teaching talents in current schools, thereby forming a faculty that can develop sustainably; third, increase research funds for English teaching, improve the hardware facilities of English teaching such as the English classrooms, key laboratories, teaching research centers, and teaching or scientific research bases, etc.; fourth, perfect the teaching management system of English majors, and set up reasonable English teaching plans and regulations.

\subsection{Improve the English curriculum system}

The courses of English writing, listening, speaking, reading and translating are an organic whole, there are complementary and mutually promotive relationships among these links, so if we want to improve the teaching quality of English writing courses, curriculum setting for only one link is far from enough, a comprehensive English curriculum system that integrates all above-mentioned links should be constructed. During the construction of the English curriculum system, on the one hand, excellent curriculum or curriculum series should be set for each link systematically, and the key teaching direction and content should be emphasized; on the other hand, the relations and connections among the various English teaching links should be constructed logically, and the fusion of these English courses should be highlighted so that different teaching links could play good promotive roles.

\section{Conclusion}

This paper analyzed the methods for evaluating the teaching quality of English writing from aspects such as literature review, expert consultation, questionnaire survey and statistical analysis, etc. Based on a few principles for the selection of evaluation indicators, from multiple perspectives and dimensions, a hierarchical evaluation system for the teaching quality of English writing based on the perspective of teachers and a hierarchical evaluation system for the teaching quality of English writing based on the perspective of students were constructed in the paper. Considering the complexity in the analysis process and the influence of multiple evaluation indicators, this paper adopted the AHP method to obtain weights of the evaluation indicators and used the grey theory to conduct grey relational analysis on the teaching quality of English writing, which provided an implementation path for the quantitative analysis 
of the teaching quality of English writing. At last, the paper proposed a few suggestions and strategies for improving the teaching quality of English writing, and selected proper countermeasures based on the quantitative analysis results, which is of great guiding significance for the teaching quality of English writing.

\section{$7 \quad$ Acknowledgement}

Xiaoqin Zhang presided over the project: Research Project of "1331 Project" in the 13th Five-Year Plan of Shanxi Education Science "Innovation Research on Practical Teaching Mode of Normal Major in Higher Vocational Colleges" (Project No.: ZX18166).

\section{References}

[1] Duran, D., Sert, O. (2019). Preference organization in English as a medium of instruction classrooms in a Turkish higher education setting. Linguistics and Education, 49: 72-85. https://doi.org/10.1016/j.linged.2018.12.006

[2] Tetteh, E.D., Qin, Z., Kwofie, B. (2019). Managing an information system transformation in higher educational institutions: A case study on CMC portal in Ghana, International Journal of Emerging Technologies in Learning, 14(22): 232-251. https://doi.org/10.3991/ij et.v14i22.11240

[3] Zhang, Y.Q. (2018). An empirical research of college business English learners' experiences of flipped classroom: A case study of business English writing course. Shandong Foreign Language Teaching, 39(1): 54-64. https://doi.org/10.16482/j.sdwy37-10 26.2018-01-006

[4] Zhang, Y.J. (2017). A study on the status quo of writing and teaching strategies in western colleges' writing classes. Course Education Research, (10): 30-31. https://doi.org/10.3969/ j.issn.2095-3089.2017.10.029

[5] Vattøy, K.D. (2020). Teachers' beliefs about feedback practice as related to student selfregulation, self-efficacy, and language skills in teaching English as a foreign language. Studies in Educational Evaluation, 64: 1-10. https://doi.org/10.1016/j.stueduc.2019.100828

[6] Li, F.W. (2019). The current situation and prospect of the research on blended teaching of English course in colleges and universities in China. Education Modernization, (35): 228230. https://doi.org/10.16541/j.cnki.2095-8420.2019.35.081

[7] Lou, H. (2019). Situational cognition of college english education based on image block gain optimization in Pseudo-Haze state, International Journal of Emerging Technologies in Learning, 14(18): 53-63

[8] Vattøy, K.D., Smith, K. (2019). Students' perceptions of teachers' feedback practice in teaching English as a foreign language. Teaching and Teacher Education, 85: 260-268. https://doi.org/10.1016/j.tate.2019.06.024

[9] Nguyen, X.N.C.M., Walkinshaw, I. (2018). Autonomy in teaching practice: Insights from Vietnamese English language teachers trained in Inner-Circle countries. Teaching and Teacher Education, 69: 21-32. https://doi.org/10.1016/j.tate.2017.08.015

[10] Irwin, D., Liu, N. (2019). Encoding, decoding, packing and unpacking via agnation: Reformulating general knowledge into disciplinary concepts for teaching English academic 
writing. Journal of English for Academic Purposes, 42: 1-8. https://doi.org/10.1016/j.jeap. $\underline{2019.100782}$

[11] Cao, X., Fu, T. (2018). Innovation research on the reform mode of English writing teaching in university. Journal of Beijing Institute of Graphic Communication, 26(1): 135137. http://doi.org/10.19461/j.cnki.1004-8626.2018.01.042

[12] Yang, H.F. (2019). The positive role of multimedia assisted instruction in college English basic writing. Education Modernization, (28): 222-223. http://doi.org/10.16541/j.cnki.2095 $-8420.2019 .28 .088$

[13] Cao, L. (2019). A comparative study of peer feedback and teacher feedback in college English writing. Education Modernization, (12): 60-61, 67. http://doi.org/10.16541/j.cnki. 2095-8420.2019.12.022

[14] Hsieh, M.C., Wang, E.M.Y., Lee, W.C., Li, L.W., Hsieh, C.Y., Tsai, W., Wang, C., Huang, J., Liu, T.C. (2018). Application of HFACS, fuzzy TOPSIS, and AHP for identifying important human error factors in emergency departments in Taiwan. International Journal of Industrial Ergonomics, 67: 171-179. https://doi.org/10.1016/j.ergo n.2018.05.004

[15] Wang, W.X. (2019). Site selection of fire stations in cities based on geographic information system (GIS) and fuzzy analytic hierarchy process (FAHP). Ingénierie des Systèmes d'Information, 24(6): 619-626. https://doi.org/10.18280/isi.240609

[16] Kumar, K. (2018). A spectrum handoff scheme for optimal network selection in NEMO based cognitive radio vehicular networks: A cost function MADM method based on grey theory based approach. Procedia Computer Science, 125: 275-281. https://doi.org/10.1016/ j.procs.2017.12.037

[17] Memon, M.S., Lee, Y.H., Mari, S.I. (2015). Group multi-criteria supplier selection using combined grey systems theory and uncertainty theory. Expert Systems with Applications, 42(21): 7951-7959. http://doi.org/10.1016/j.eswa.2015.06.018

[18] Butdee, S., Phuangsalee, P. (2019). Uncertain risk assessment modelling for bus body manufacturing supply chain using AHP and fuzzy AHP. Procedia Manufacturing, 30: 663670. https://doi.org/ 10.1016/j.promfg.2019.02.094

[19] Di Angelo, L., Di Stefano, P., Fratocchi, L., Marzola, A. (2018). An AHP-based method for choosing the best 3D scanner for cultural heritage applications. Journal of Cultural Heritage, 34: 109-115. https://doi.org/10.1016/j.culher.2018.03.026

[20] Acar, C., Beskese, A., Temur, G.T. (2018). Sustainability analysis of different hydrogen production options using hesitant fuzzy AHP. international journal of hydrogen energy, 43(39): 18059-18076. https://doi.org/10.1016/j.ijhydene.2018.08.024

[21] Lai, C.M. (2019). Integrating simplified swarm optimization with AHP for solving capacitated military logistic depot location problem. Applied Soft Computing, 78: 1-12. https://doi.org/10.1016/j.asoc.2019.02.016

[22] Muhsen, D.H., Haider, H.T., Al-Nidawi, Y.M., Khatib, T. (2019). Domestic load management based on integration of MODE and AHP-TOPSIS decision making methods. Sustainable Cities and Society, 50: 1-14. https://doi.org/10.1016/j.scs.2019.101651

[23] Maghrabie, H.F., Beauregard, Y., Schiffauerova, A. (2019). Grey-based multi-criteria decision analysis approach: Addressing uncertainty at complex decision problems. Technological Forecasting and Social Change, 146: 366-379. https://doi.org/10.1016/j.tec hfore.2019.05.031

[24] Rajesh, R. (2020). A grey-layered ANP based decision support model for analyzing strategies of resilience in electronic supply chains. Engineering Applications of Artificial Intelligence, 87: 1-18. https://doi.org/10.1016/j.engappai.2019.103338 
[25] Baranitharan, P., Ramesh, K., Sakthivel, R. (2019). Multi-attribute decision-making approach for Aegle marmelos pyrolysis process using TOPSIS and Grey Relational Analysis: Assessment of engine emissions through novel Infrared thermography. Journal of Cleaner Production, 234: 315-328. https://doi.org/10.1016/j.jclepro.2019.06.188

\section{Authors}

Xiaoqin Zhang was born in Shanxi, China in 1978. She received the master's degree from Shanxi Normal University. Now works at Yuncheng Advanced Normal College, China (ycszzxq0359@163.com). Her research interest includes English education, practical teaching.

Shengxin Wang was born in Sichuan, China in 1999. Now he is studying for Bachelor of Engineering in Southwest University, China (wsx870101364@ email.swu.edu.cn). His research interests include computer, program and so on.

Yanling Cao was born in Tianchang, Anhui, China in 1986. She received the Doctoral degree from Sun Yat-sen University, China. Now she works in school of design, South China University of Technology (sdylcao@scut.edu.cn). Her research interests include Philosophy, Aesthetics, History of Art.

Guangqi Chen was born in Shanxi, China in 1979. He received the master's degree from Shanxi Normal University. Now works at Yuncheng Kangjie Middle School, China (yckjcgq0359@163.com). His research interest includes English education, English teaching.

Article submitted 2020-05-10. Resubmitted 2020-06-24. Final acceptance 2020-06-30. Final version published as submitted by the authors. 